$\begin{array}{llllll}\text { REVISION } & \text { BIBLIOGRAFICA } & \text { Y } & \text { EXTRACTOS } & \text { DE } & \text { REVISTAS }\end{array}$

\title{
RESULTADOS EN EL TRATAMIENTO DE FORMAS PRE- CLINICAS DEL CARCINOMA DEL CUELLO UTERINO
}

\section{J. P. A. Latour}

American Journal of Obstetrics and Gynecology. Vol. 81 № 3 - Marzo 1961

Se presentan 274 casos de Carcinoma de Cuello, diagnosticados en un período de 10 años por medio de la citología vaginal y la conización. Ninguno de estos casos presentaba signos clínicos evidentes al examen pélvico.

Se dividen en dos grupos: 136 carcinomas intraepiteliales y 138 carcinomas tempranamente invasivos, estado I.

El autor hace alusión a la clasificación del Ca de cuello propuesta por Kottmeier (Am. J. Obs. \& Gynec. 76: 243) anotando sus ventajas.

La edad de las pacientes con estado clínico I fue 10 años mayor a las de aquellas con estado I pre-clínico.

Los tratamientos efectuados fueron divididos en 5 grupos asi :

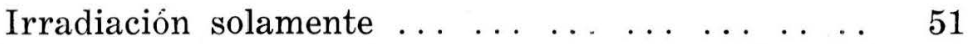

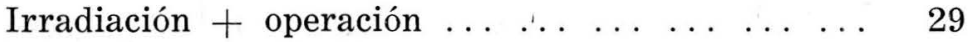

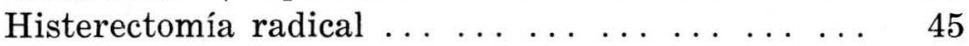

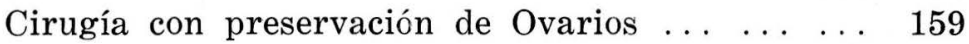

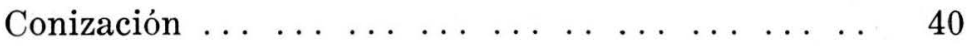

Los resultados obtenidos revelaron que la supervivencia de 5 años, para el grupo en la primera mitad del trabajo (19501954) fue de $96.1 \%$ para el estado $0,95.4 \%$ para el estado I preclínico y de $73.1 \%$ para el estado I clínico.

En ese primer grupo se hallaban 51 carcinomas intraepiteliales 16 de los cuales solo recibieron conización. De los 88 casos de carcinoma invasivo preclínico en los primeros 5 años, solamente 10 fueron tratados por cirugía radical. 
Los autores consideran que han obtenido una supervivencia del $100 \%$ en los casos tratados en los primeros 5 años puesto que ninguna de las pacientes había muerto por cáncer uterino. Concluyen que el carcinoma cervical "preclínico" responde bien a una variedad de tratamientos y que solo excepcionalmente parece hallarse la necesidad para irradiación o cirugía radical, siendo suficiente en la gran mayoría de los casos la histerectomía total con resección de cúpula vaginal y conservación de ovarios.

Uno de los comentaristas del trabajo, hace énfasis en el hecho de que gracias al tratamiento conservador en una gran parte de las pacientes, se obtuvieron 13 embarazos normales y por otra parte en los casos tratados con cirugía radical o irradiación se produjeron $\mathbf{1 1 . 7 \%}$ de fístulas. Por otra parte varios de los comentaristas critican el hecho de tratar el Ca estado I preclínico en forma diferente del Ca invasivo estado I.

J. V.M.

\section{PROLAPSO DEL CORDON UMBILICAL, INCLUYENDO}

\section{CONTROLES TARDIOS DE FETOS SOBREVIVIENTES}

\section{Por Irwin M. Cushner M.D. (Hosp. Johns Hopkins)}

American Journal of Obstetrics and Gynecology. Vol. 81 No 4 - Abril 1961

Se presenta inicialmente una muy completa revisión bibliográfica del tema en cuestión. El material consiste de 87.963 partos sobre un período de 61 años durante los cuales la incidencia del prolapso del cordón fué de $0.48 \%$.

Como factor común etiológico se encontró la falta de llenamiento del estrecho superior de la pelvis en el momento de la ruptura de las membranas. En detalle como factores etiológicos principales: Presentación anormal 49\%, pelvis estrechas $30 \%$, prematurez $22 \%$, embarazo múltiple $10 \%$.

Respecto al tratamiento inmediato del cordón prolapsado los autores hacen énfasis en aquellas maniobras que alivien la presión sobre el cordón, esto es principalmente: posición de Trendelemburg y elevación manual de la presentación, así como reposición del cordón. 
El tipo de parto debe ser por cesárea en caso de ser éste inminente por vía vaginal una vez hecho el diagnóstico de esta complicación. Entre los diferentes tipos de conductas, la operación cesárea produjo el más bajo índice de mortalidad fetal perinatal con un $11 \%$ en contraste con cifras entre 32 a $58 \%$ para la extracción podálica, el parto espontáneo o la aplicación de fórceps.

Los controles efectuados tardíamente en niños nacidos con prolapso del cordón revelaron que el $95 \%$ han sido enteramente normales en cuanto a desarrollo somático e intelectual. Este dato le resta mucho valor a la hipótesis de posible anoxia cerebral severa en el momento del parto o del trabajo del parto en este tipo de pacientes.

J. V.M.

PRESENTACION DE PELVIS EN PRIMIPARAS - 189 Casos Por Richard L. Jackson

American Journal of Obstetrics and Gynecology. Vol. 81 No 4 - Abril 1961

La mortalidad fetal en este estudio fue de $11 \%$ con un $22 \%$ de infantes prematuros en el total de 189 casos. En el grupo de pacientes que recibieron ocitócicos la mortalidad fetal subió a $20 \%$ en contraste con $9.5 \%$ en el grupo que no recibió ocitócicos.

La duración promedio del trabajo de panto fue en las pacientes que recibieron ocitócicos de 138 minutos promedio por encima del grupo control sin estimulación alguná aterina.

El número de operaciones cesáreas fué del $8.7 \%$.

Los autores concluyen que la estimulación de úteros inertes por medio de ocitócicos trae aumento de la morbilidad y de la mortalidad fetales en las presentaciones de pelvis en pacientes primíparas. Además anotan que si se usan los ocitócicos debe ser luego de evaluación muy cuidadosa de sus indicaciones y solo por dos horas, al final de las cuales si el parto no es inminente por la vía vaginal, debe practicarse de inmediato la operación cesárea.

J. V.M. 